\title{
Association between serum zinc levels and lung cancer: a meta-analysis of observational studies
}

\author{
Ying Wang ${ }^{1}$, Zhengyi Sun ${ }^{1}$, Aipeng $\mathrm{Li}^{2}$ and Yongsheng Zhang ${ }^{3 *}$
}

\begin{abstract}
Background: Inconsistent results according to numerous studies that had investigated the association between serum zinc levels and lung cancer risk were reported. The aim of this study was to explore whether serum zinc levels were lower in lung cancer patients than that in controls.

Methods: We systematically retrieved the databases of PubMed, Wanfang, Cochrane, ScienceDirect website, CNKI, and SinoMed databases for comprehensive relevant studies published before December 2018 and conducted a meta-analysis. Standard mean differences (SMD) were pooled using a random effects model.

Results: Thirty-two articles were eligible to investigate the correlation between serum zinc levels and lung cancer risk, involving 2894 cases and 9419 controls. The pooled results showed sufficient evidence approving the association between serum zinc levels and lung cancer risk. And the serum zinc levels in lung cancer were significantly lower than that in controls (summary SMD $=-0.88,95 \%$ confidence interval $(C \mathrm{l})=-0.94,-0.82$ ). Meanwhile, consistent results were obtained both in European populations and Asian populations. No publication bias was detected in our analysis.

Conclusions: The present meta-analysis suggested that serum zinc levels were significantly lower in lung cancer patients than that in controls.
\end{abstract}

Keywords: Serum zinc or serum zinc level, Lung cancer, Meta-analysis

\section{Introduction}

Cancer is a crucial health problem on a global scale that has become one of the primary causes of death. The increasing trend in cancer globally could be slowed and reversed if preventive measures could provide the feasible approach [1]. As we all know, smoking had been as the well-known role in the development of lung cancer [2]. Previous studies had confirmed that some external environment exposure [3, 4], dietary factors $[5,6]$, and physical activities [7] could affect the risk of lung cancer. However, some trace element concentrations, such as zinc, copper, and so on, could also influence the development of lung cancer. A recent meta-analysis had been performed to explore the relationship about serum copper levels in lung cancer [8]. Copper and zinc are closely related trace

\footnotetext{
* Correspondence: zhang__ysh@126.com

${ }^{3}$ Center for Reproductive Medicine and Center for Prenatal Diagnosis, The First Hospital of Jilin University, No. 71, Xinmin Street, Changchun 130021, Jilin Province, China

Full list of author information is available at the end of the article
}

elements. Zinc is used for the growth of cells and is also useful in maintaining the integrity of the cell membrane. Therefore, cancer cells may consume zinc in the circulation to maintain cancer growth and maintain its membrane integrity [9]. However, there has not been an article attempting to summarize the results for serum zinc levels on the risk of lung cancer. So far, numerous researchers have examined potential effects of serum zinc levels on lung cancer risk, but existing epidemiological data are inconsistent. Hence, we aimed to evaluate results from previous studies systematically and carefully by constructing a meta-analysis of observational studies to find whether serum zinc levels were lower in lung cancer patients than that in controls.

\section{Methods}

This meta-analysis was designed and performed according to the guidelines of the preferred reporting items for 
systematic reviews and meta-analyses (PRISMA compliant) statement [10].

\section{Data sources and searches}

A comprehensive, computerized literature search regarding the association between serum zinc levels and lung cancer risk was conducted in six databases (PubMed, Wanfang, Cochrane, ScienceDirect website, CNKI, and SinoMed databases), from their inception to December 2018. Combinations of the following keywords were used for the search: "zinc levels" OR "zinc concentration" OR "zinc" OR "trace element" in combination with "lung cancer" OR "lung tumor". Moreover, we also scrutinized the references of retrieved publications to identify any studies that were potentially missed.

\section{Study selection criteria}

To be eligible for our analysis, the studies had to meet the following criteria: (1) epidemiological studies; (2) the aim was to evaluate the associations between serum zinc levels and lung cancer risk; (3) the numbers, mean, and standard deviation (SD) of serum zinc levels for cases and control are available. It is noted that duplicated results may be published in more than one paper, so we selected the most recent or most informative paper in our analysis.

\section{Data extraction and quality assessment}

Two of the authors extracted all data independently, complying with the selection criteria above. A standardized data collection protocol was as follows: the last name of the first author, publication year, study design, the location of the study conducted in, subject in cases and control, gender, range or mean age of cases, method of measurement for serum zinc, and mean and SD of serum zinc levels for cases and control.

\section{Statistical analysis}

The strength of the association between serum zinc levels and lung cancer risk was measured by standard mean differences (SMD) and 95\% confident interval (CI) by adopting random effects models that taking into account both within-study and between-study variations [11]. The analysis evaluated heterogeneity among researches via the Cochran's $Q$ test and $I^{2}$ (inconsistency index) statistic [12]. Subgroup analysis based on study design and geographic location was conducted in this meta-analysis to explore possible heterogeneity and to analyze whether there was a correlation in some subgroups. The meta-regression analysis was also performed to examine the possible heterogeneity [13]. Furthermore, sensitivity analysis was done to estimate the stability of the results by removing each study from the analysis, one at a time, which can evaluate the influence of a single comparison on the overall risk estimate. We also adopted Begg's funnel plots [14] and Egger's linear regression test [15] to evaluate whether publication bias existed. All the statistical analyses involved were performed with STATA software. $P$ values were two-sided and less than 0.05 was considered statistically significant.

\section{Results}

\section{Literature search and study characteristics}

The specific step of searching and selecting relevant articles was summarized in Fig. 1. To sum up, we retrieved 204 articles from PubMed, 231 articles from Wanfang databases, 198 articles from Cochrane, 221 articles from ScienceDirect website, 265 articles from CNKI, and 248 articles from SinoMed databases. Fifty-nine articles were reviewed in full text. By evaluating the full text, 27 articles were further excluded owing to listed reasons below: review articles $(n=13)$, not reported mean or SD $(n=7)$, reported dietary factors $(n=5)$, and letter to the editor $(n=2)$. Ultimately, 32 articles [16-47] met the inclusion criteria. Three studies came from Europe and the

\section{4 articles found from PubMed \\ 231 articles found from WanFang databases 198 articles found from Cochrane 221 articles found from ScienceDirect website 265 articles found from CNKI 248 articles found from SinoMed databases}

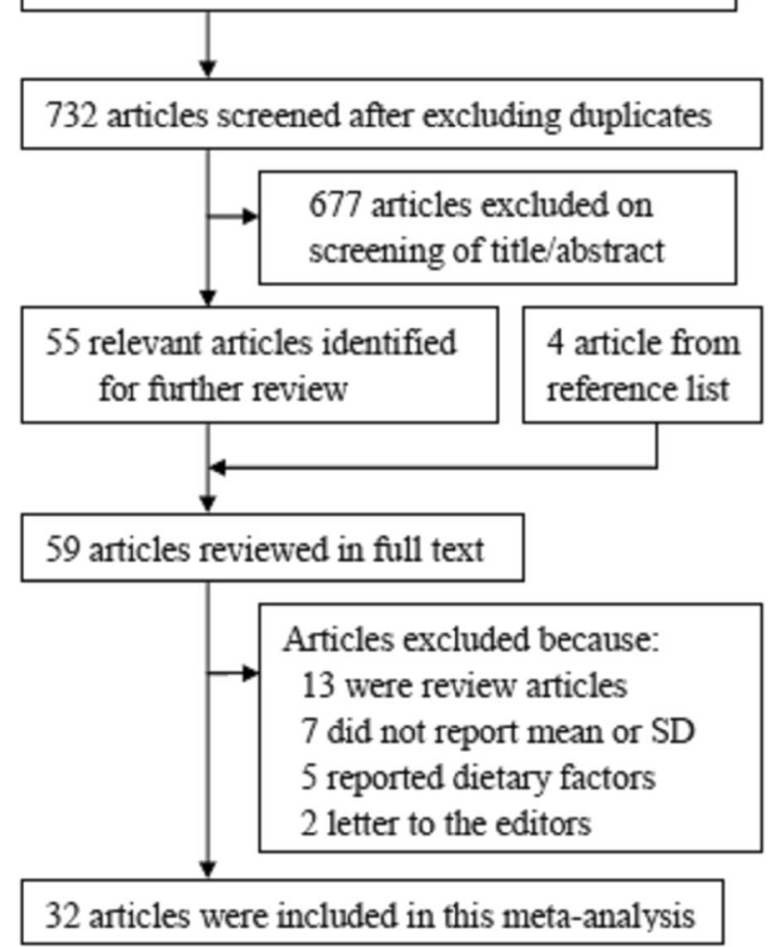

Fig. 1 Flow diagram of the literature search 


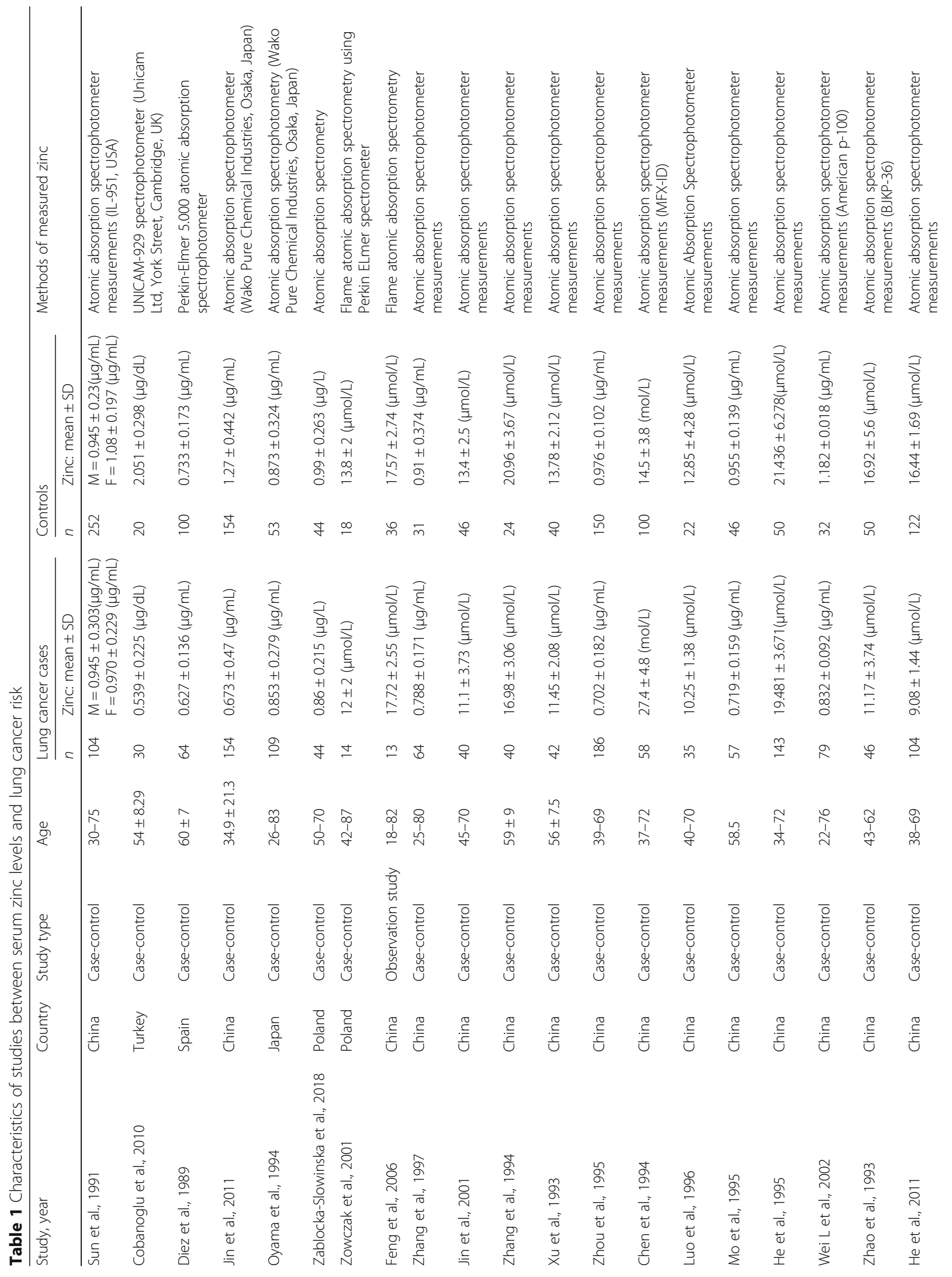




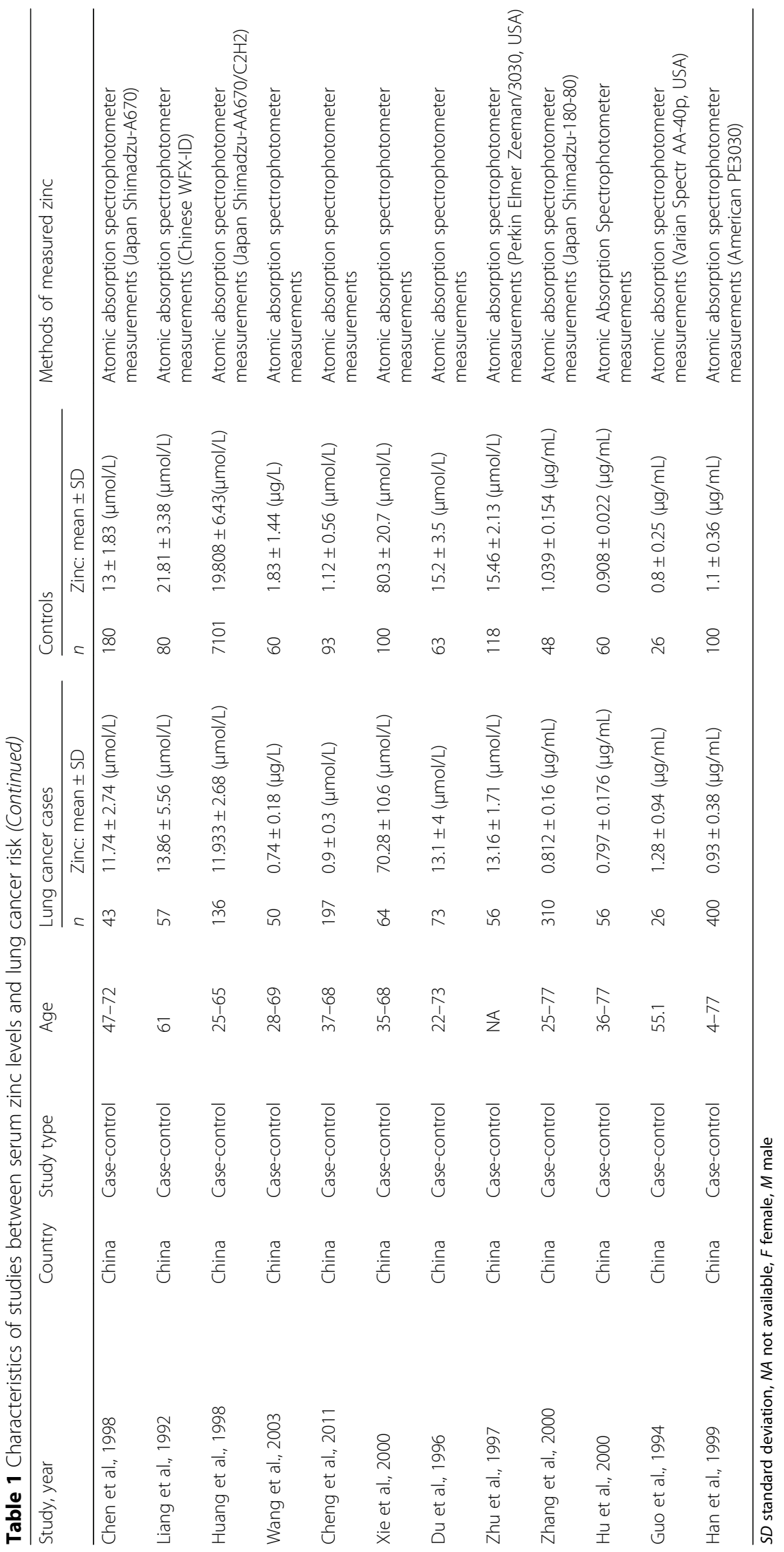


remaining 29 studies were from Asia. The characteristics of the included studies are shown in Table 1.

\section{Serum zinc levels and lung cancer risk}

In each study included in our analysis, 27 studies suggested that serum zinc levels were lower in lung cancer patients than that in controls, while four studies found a non-significant association between serum zinc levels and lung cancer. However, two studies obtained a positive association between serum zinc levels and lung cancer. Figure 2 has demonstrated the investigation results of the association between serum zinc levels and lung cancer in all the articles, as serum zinc levels in lung cancer were significantly lower than controls (summary $\mathrm{SMD}=-0.88,95 \% \mathrm{CI}=-0.94,-0.82, Z$ value $=28.32, P$ for $Z$ test $<0.001)$. Extreme heterogeneity was present among the pooled results $\left(P<0.001, I^{2}=96.5 \%\right)$. Based on Egger's test $(P=0.548)$ and the Begg's funnel plot (Fig. 3), there existed no publication bias.

\section{Stratified analysis}

Subgroup analyses by study design and geographic location were conducted to further examine serum zinc levels and lung cancer risk. We found lower serum zinc levels in lung cancer patients than that in controls both in European populations (summary $\mathrm{SMD}=-0.65,95 \% \mathrm{CI}=$ $-0.89,-0.41, Z$ value $=5.25, P$ for $Z$ test $\left.<0.001, I^{2}=0.0 \%\right)$ and Asian populations (summary SMD $=-0.90,95 \% \mathrm{CI}=$ $-0.96,-0.83, Z$ value $=27.90, P$ for $Z$ test $<0.001, I^{2}=$ $96.8 \%)$. Thirty-one of the 32 studies were case-control

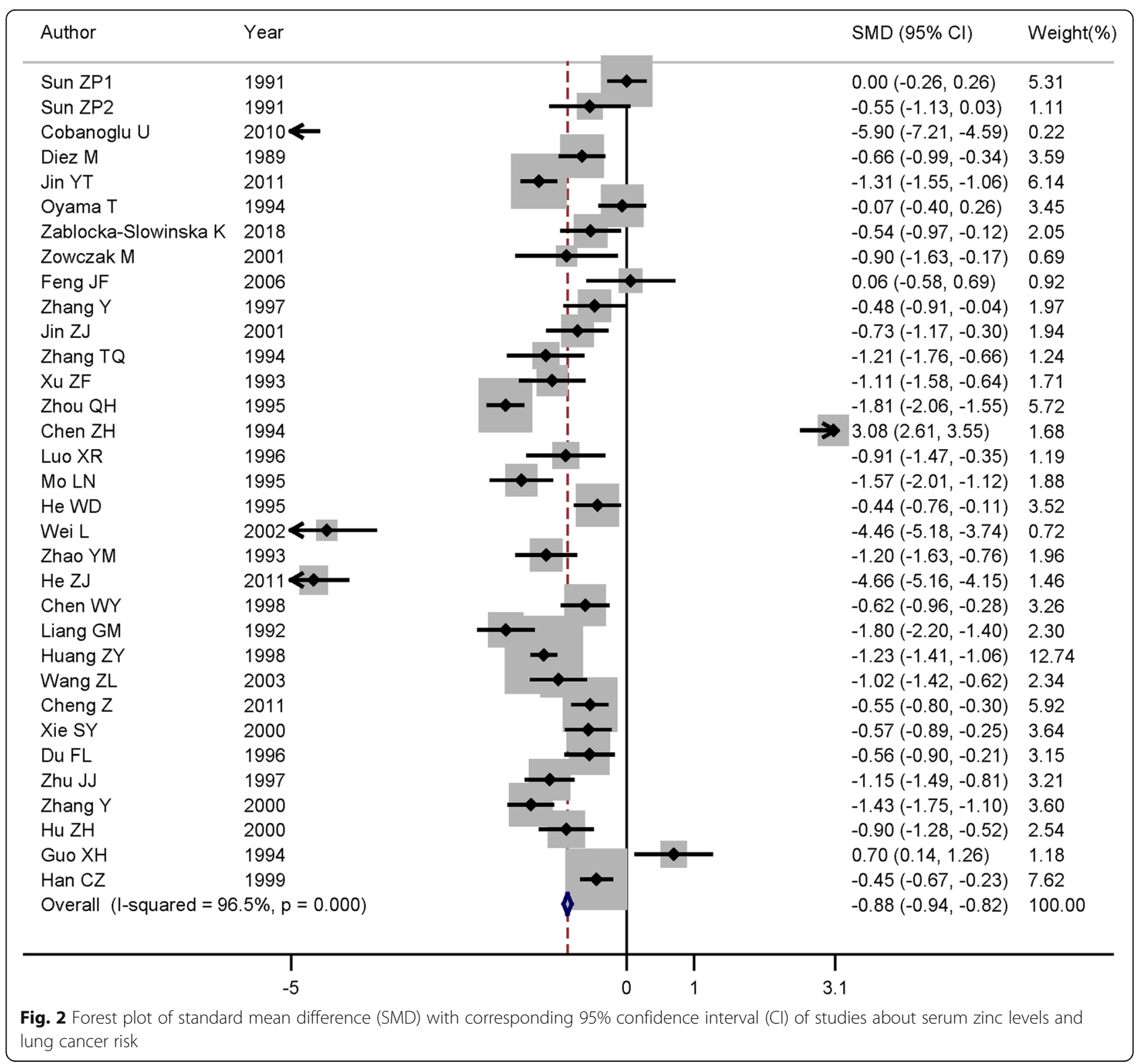




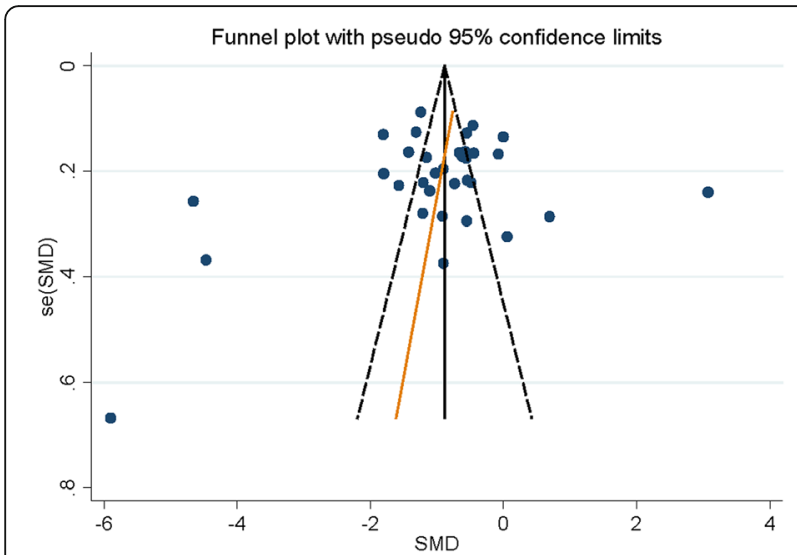

Fig. 3 Funnel plot about serum zinc levels and lung cancer risk

studies, and the result was consistent with the overall result (summary SMD $=-0.89,95 \% \mathrm{CI}=-0.95,-0.83, Z$ value $=$ 28.47, $P$ for $Z$ test $\left.<0.001, I^{2}=96.6 \%\right)$.

\section{Meta-regression analysis}

Meta-regression analysis was evaluated in this article, indicating that no source of heterogeneity was observed in the association between serum zinc levels and lung cancer risk.

\section{Sensitivity analysis}

Sensitivity analysis indicated that no evidence of overall result changing was observed when removed each study from the analysis, one at a time.

\section{Discussion}

The meta-analysis was conducted to investigate the association between serum zinc levels and lung cancer. Findings from our report suggested that serum zinc levels in lung cancer cases were significantly lower than that in controls. Consistent results were found both in European populations and Asian populations.

Some previous studies had been published to explore serum element levels and lung cancer risk. Chen et al. performed a meta-analysis with 13 publications to assess the association between serum iron levels and lung cancer risk [48]. The authors concluded that serum iron levels had no effect on the risk of lung cancer. Song et al. found no significant association between serum magnesium levels and lung cancer risk when pooled 11 suitable papers [49]. However, Zhang et al. performed a meta-analysis using 33 articles to explore the association between serum copper levels and the risk of lung cancer [8]. Results from their study suggested that serum copper levels were higher in lung cancer than that in controls. Copper and zinc are closely related trace elements involved in cell proliferation, growth, gene expression, apoptosis, and other processes. These two trace elements are all necessary for the proper activity of superoxide dismutase due to their integral role as cofactors or ions stabilizing the molecular structure [50]. Zinc deficiency may have adverse events, especially on immune function [51]. Gómez et al. had studied the association of zinc and its role in lung cancer [52]. In general, zinc microenvironment may play a key role in oxidative stress, apoptosis, and/or cell signaling alterations which influence the behavior of malignant cancer cells [52], and this may play a role in preventing lung cancer.

Previous studies had significantly revealed that serum zinc had a protective effect on some cancers. Xie et al. conducted a meta-analysis about serum zinc levels and cervical cancer, indicating that serum zinc levels were lower in cervical cancer patients than controls [53]. In addition, Mao et al. found that bladder cancer patients had lower serum zinc levels compared with controls [54]. Moreover, a meta-analysis published by Zhao et al. suggested that serum zinc concentrations in prostate cancer patients were significantly lower than those in normal controls [55]. Our results were consistent with the abovementioned studies.

However, there are some limitations and potential bias that must be acknowledged in our meta-analysis. First, we only included papers published in English or Chinese, which may omit some other language paper. Furthermore, we only searched published articles, which may omit some unpublished articles or some meeting articles. These factors may yield between-study heterogeneity and publications bias in the overall pooled results. Second, although most method of measurement for serum zinc was using atomic absorption spectrophotometer, different methods of measurement as well as a different instrument could also cause between-study heterogeneity. Third, evidence of high heterogeneity was found, both in overall and subgroup analysis, in our analysis. However, we could not find the source of heterogeneity due to stratified analysis and meta->regression analysis concerning the relationship between serum zinc levels and lung cancer risk. Fourth, our meta-analysis included three articles from Europe and 29 articles from Asia, thus, further epidemiological studies are warranted in the future to assess the association between serum zinc levels and lung cancer risk.

\section{Conclusions}

In summary, our meta-analysis, which included a large number of subjects of 32 articles, manifested that serum zinc levels were significantly lower in lung cancer patients than that in controls.

\section{Abbreviations}

SMD: Standard mean differences; Cl: Confidence interval; SD: Standard deviation

\section{Acknowledgements}

None 


\section{Funding}

None

\section{Availability of data and materials}

The tables and figures supporting the conclusions of this article are included within the article.

\section{Authors' contributions}

YW and YSZ conceived and designed the study. YW, ZYS, and APL participated in data collecting. YW analyzed the data. YW and YSZ commented on drafts of the paper. All authors read and approved the final manuscript.

\section{Ethics approval and consent to participate}

Not applicable

\section{Consent for publication}

Not applicable

\section{Competing interests}

The authors declare that they have no competing interests.

\section{Publisher's Note}

Springer Nature remains neutral with regard to jurisdictional claims in published maps and institutional affiliations.

\section{Author details \\ ${ }^{1}$ Institute of Pediatrics, The First Hospital of Jilin University, Changchun 130021, Jilin Province, China. ²Department of Ophthalmology, The First Hospital of Jilin University, Changchun 130021, Jilin Province, China. ${ }^{3}$ Center for Reproductive Medicine and Center for Prenatal Diagnosis, The First Hospital of Jilin University, No. 71, Xinmin Street, Changchun 130021, Jilin Province, China.}

\section{Received: 17 February 2019 Accepted: 16 April 2019}

\section{Published online: 06 May 2019}

\section{References}

1. Thun MJ, JO DL, Center MM, et al. The global burden of cancer: priorities for prevention. Carcinogenesis. 2010;31(1):100-10.

2. O'Keeffe LM, Taylor G, Huxley RR, et al. Smoking as a risk factor for lung cancer in women and men: a systematic review and meta-analysis. BMJ Open. 2018;8(10):e021611.

3. Jia PL, Zhang C, Yu JJ, et al. The risk of lung cancer among cooking adults: a meta-analysis of 23 observational studies. J Cancer Res Clin Oncol. 2018; 144(2):229-40

4. Mundt KA, Dell LD, Crawford $L$, et al. Cancer risk associated with exposure to bitumen and bitumen fumes: an updated systematic review and metaanalysis. J Occup Environ Med. 2018;60(1):e6-e54.

5. Chen G, Wang J, Hong X, et al. Dietary vitamin E intake could reduce the risk of lung cancer: evidence from a meta-analysis. Int J Clin Exp Med. 2015; 8(4):6631-7.

6. Lin X, Liu L, Fu Y, et al. Dietary cholesterol intake and risk of lung cancer: a meta-analysis. Nutrients. 2018;10(2).

7. Zhong S, Ma T, Chen L, et al. Physical activity and risk of lung cancer: a meta-analysis. Clin J Sport Med. 2016;26(3):173-81.

8. Zhang X, Yang Q. Association between serum copper levels and lung cancer risk: a meta-analysis. J Int Med Res. 2018. https://doi.org/10.1177/ 0300060518798507.

9. Schwartz MK. Role of trace elements in cancer. Cancer Res. 1975:35(11 Pt. 2):3481-7.

10. Moher D, Liberati A, Tetzlaff J, et al. Preferred reporting items for systematic reviews and meta-analyses: the PRISMA statement. BMJ. 2009;339:b2535

11. DerSimonian R, Laird N. Meta-analysis in clinical trials. Control Clin Trials. 1986;7(3):177-88.

12. Higgins JP, Thompson SG, Deeks JJ, et al. Measuring inconsistency in metaanalyses. BMJ. 2003;327(7414):557-60

13. Higgins JP, Thompson SG. Controlling the risk of spurious findings from meta-regression. Stat Med. 2004;23(11):1663-82.

14. Begg CB, Mazumdar M. Operating characteristics of a rank correlation test for publication bias. Biometrics. 1994;50(4):1088-101.

15. Egger M, Davey Smith G, Schneider M, et al. Bias in meta-analysis detected by a simple, graphical test. BMJ. 1997;315(7109):629-34.
16. Sun ZP, Meng SX, Xu PY, et al. Study on serum copper and zinc levels and copper/zinc ratio in 102 lung cancer patients. Trace Elem Health Res. 1991;1:67-9.

17. Cobanoglu U, Demir H, Sayir F, et al. Some mineral, trace element and heavy metal concentrations in lung cancer. Asian Pac J Cancer Prev. 2010; 11(5):1383-8.

18. Diez M, Arroyo M, Cerdan FJ, et al. Serum and tissue trace metal levels in lung cancer. Oncology. 1989;46(4):230-4.

19. Jin $\mathrm{Y}$, Zhang $\mathrm{C}, \mathrm{Xu} \mathrm{H}$, et al. Combined effects of serum trace metals and polymorphisms of CYP1A1 or GSTM1 on non-small cell lung cancer: a hospital based case-control study in China. Cancer Epidemiol. 2011;35(2):182-7.

20. Oyama T, Matsuno K, Kawamoto T, et al. Efficiency of serum copper/zinc ratio for differential diagnosis of patients with and without lung cancer. Biol Trace Elem Res. 1994;42(2):115-27.

21. Zablocka-Slowinska K, Placzkowska S, Prescha A, et al. Serum and whole blood $\mathrm{Zn}, \mathrm{Cu}$ and $\mathrm{Mn}$ profiles and their relation to redox status in lung cancer patients. J Trace Elem Med Biol. 2018;45:78-84.

22. Zowczak M, Iskra M, Paszkowski J, et al. Oxidase activity of ceruloplasmin and concentrations of copper and zinc in serum of cancer patients. J Trace Elem Med Biol. 2001;15(2-3):193-6.

23. Feng JF, Li SL. Correlation between oxidative stress and trace elements in blood of patients with cancer. Chin J of Clinic Reh. 2006;10(4):187-90.

24. Zhang Y. Clinical significance of determination of serum lead, zinc and copper to zinc ratio in patients with lung cancer. Trace Elem Sci Guangdong. 1997;4(3):32-4.

25. Jin ZJ, Qian LQ, Dong GQ, et al. Measurement and analysis of serum copper, zinc and magnesium in patients with lung cancer and gastric cancer. Shaanxi Med J. 2001;30(3):165-6.

26. Zhang $T Q$, Yao RL, Song MC. Copper, zinc and copper-zinc ratio in plasma of patients with lung cancer. Shaanxi Med J. 1994;25(4):349-51.

27. Xu ZF, Sun YC, Zhang CW, et al. Clinical significance of changes of serum copper, zinc and magnesium contents in patients with lung cancer. J Second Mil Med Univ. 1993;14(2):195-6.

28. Zhou QH, Luo YY, Li CF, et al. A study on serum copper and zinc levels in patients with lung cancer. Chinese J Clin Thorac Cardiovasc Surg. 1995;2(1):45-7.

29. Chen ZH, Chen NJ, Chen LJ, et al. Detection of serum copper, zinc and iron in patients with lung cancer and lung infection and its clinical significance. J Guangzhou Med Coll. 1994;12(2):118-9.

30. Luo XR, Mao WG. Changes of serum copper and zinc in patients with lung cancer and its clinical significance. Hunan Med. 1996;13(3):136-7.

31. Mo LN, Du KX, Liu GC. Analysis of serum CEA and trace elements Zn and Cu in patients with lung cancer. Radioimmunology. 1995;8(6):354-5.

32. He WD. Detection and analysis of some trace elements in serum of patients with lung cancer. Jiujiang Med J. 1995;10(2):69-71.

33. Wei L, Ji QM, Xue DY, et al. The role of copper and zinc determination in patients with lung cancer. Chinese Tumor. 2002;11(3):182-3.

34. Zhao YM, Zhang XP. The value of serum copper and zinc levels and their ratio in diagnosis of lung cancer. Shanghai Med Inspection J. 1993;8(2):120-21.

35. He ZJ. Detection of serum trace elements in lung cancer patients and its significance. Med Innovation of China. 2011:8(18):118-9.

36. Chen WY. Changes of serum trace elements copper and zinc in patients with lung cancer. Zhejiang Med. 1998;20(6):330-1.

37. Liang GM, Zhu XH, Wang X. Serum zinc and copper levels and copper/zinc ratios in patients with lung cancer. Cancer Res. 1992;19(3):193-4.

38. Huang ZY, Hu FD. Comparative study of serum trace elements in patients with lung cancer. Shanxi Clin Med J. 1998;17(2):114-6.

39. Wang ZL, Zhang W, Zhang HY, et al. Determinat ion of serum trace elements and their clinical value in patients with lung cancer. Clin Focus. 2003;18(4):183-5.

40. Cheng Z, Dai LL, Kang Y, et al. Detection of trace elements of patients with lung cancers and pulmonary infections and its clinical significance. Chin J Nosocomiol. 2011;21(10):2006-8.

41. Xie SY, Chen YX. Analysis of 64 cases of lung cancer with trace elements copper and zinc. Shanxi Med J. 2000;29(2):83-4.

42. Du FL, Li ZM, Cao MJ, et al. Determination of serum copper, zinc, magnesium and iron in patients with pulmonary tuberculosis, chronic bronchitis, pulmonary heart disease and lung cancer. J of Xi'an Med Univ. 1996;17(3):348-50.

43. Zhu JJ, Duan XY, Liu JS. The diagnostic value of serum copper and zinc concentrations in lung cancer, pulmonary tuberculosis and pulmonary infection. China J Modern Med. 1997;7(10):11-3.

44. Zhang Y, Li X. Relationship of serum trace elements to lung cancer. Trace Elem Health Res. 2000;17(3):15-7. 
45. Hu ZH, Ren Q, Guo J, et al. Significance of determination of serum zinc, copper and copper/zinc ratio on evaluating diagnosis therapeutic effect and prognosis of lung cancer. Trace Elem Sci Guangdong. 2000;7(1):19-22.

46. Guo XH, Li PF, Peng FK, et al. Relationship between serum zinc, copper, manganese and lung cancer. Chin Pub Heal. 1994;10(4):156-7.

47. Han CZ, Zhao XW, Jing JX, et al. [Evaluation of the serum copper zinc levels and copper/zinc ratio in the diagnosis of malignant tumor]. Chinese Tumor. 1999;8(12):572-73

48. Chen HF, Wu LX, Li XF, et al. A meta-analysis of association between serum iron levels and lung cancer risk. Cell Mol Biol (Noisy-le-grand). 2018;64(13):33-7.

49. Song $X$, Zhong $X$, Tang $K$, et al. Serum magnesium levels and lung cancer risk: a meta-analysis. World J Surg Oncol. 2018;16(1):137.

50. Aguirre JD, Culotta VC. Battles with iron: manganese in oxidative stress protection. J Biol Chem. 2012;287(17):13541-8.

51. Grattan BJ, Freake HC. Zinc and cancer: implications for LIV-1 in breast cancer. Nutrients. 2012;4(7):648-75.

52. Gómez NN, Biaggio VS, Ciminari ME, et al. Zinc: What is your role in lung cancer? Nutr Defic. 2016;Chapter 3:47-53.

53. Xie $Y$, Wang J, Zhao $X$, et al. Higher serum zinc levels may reduce the risk of cervical cancer in Asian women: a meta-analysis. J Int Med Res. 2018;46(12):4898-906.

54. Mao S, Huang S. Zinc and copper levels in bladder cancer: a systematic review and meta-analysis. Biol Trace Elem Res. 2013;153(1-3):5-10.

55. Zhao J, Wu Q, Hu X, et al. Comparative study of serum zinc concentrations in benign and malignant prostate disease: a systematic review and metaanalysis. Sci Rep. 2016;6:25778.

Ready to submit your research? Choose BMC and benefit from:

- fast, convenient online submission

- thorough peer review by experienced researchers in your field

- rapid publication on acceptance

- support for research data, including large and complex data types

- gold Open Access which fosters wider collaboration and increased citations

- maximum visibility for your research: over $100 \mathrm{M}$ website views per year

At $\mathrm{BMC}$, research is always in progress.

Learn more biomedcentral.com/submissions 